\title{
Cardiovascular Image
}

\section{Mechanical Prosthetic Valve Thrombosis}

Márcio Silva Miguel Lima e Marcelo Luiz Campos Vieira

Instituto do Coração (Incor) - HCFMUSP

A 51-year-old female patient with a double-disk mechanical mitral valve prosthesis for one year had a history of inadequate use of anticoagulation therapy and developed progressive dyspnea. On admission to the emergency room of InCor, Sao Paulo, she presented respiratory distress, tachypnea, BP of 80/40 $\mathrm{mmHg}$, jugular venous distension and pulmonary crackles. Transesophageal echocardiography was performed one hour after admission, and showed a large thrombus adhered to the mechanical prosthesis with restriction to disk motion; reduced prosthetic valve area $\left(\mathrm{VA}=0.6 \mathrm{~cm}^{2}\right)$; increased gradients (peak gradient of $38 \mathrm{mmHg}$ and mean gradient of $26 \mathrm{mmHg}$ ); and moderate paraprosthetic leak. Emergency surgery was indicated; however, the patient died immediately before the procedure due to cardiovascular collapse.

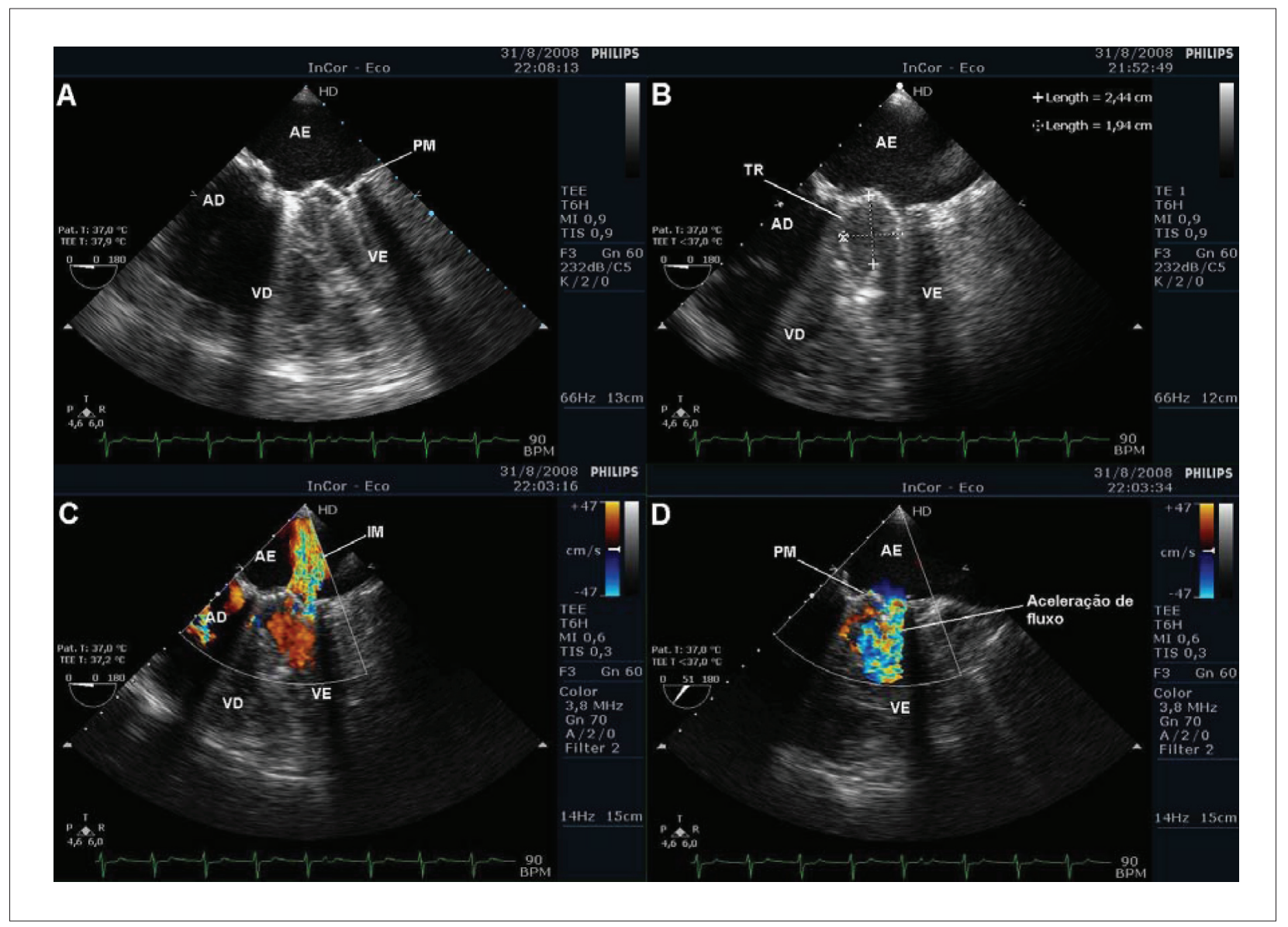

Fig. 1 - A and B - Transesophageal echocardiogram showing large thrombus adhered to the prosthetic mitral valve with reduced area; C - moderate paraprosthetic leak on color-Doppler-flow mapping; $D$ - clear flow acceleration consistent with reduced prosthetic valve area LA - left atrium, RA - right atrium, LV - left ventricle, RV - right ventricle, MP - mechanical prosthesis, $T H$ - thrombus, MR - mitral regurgitation

\section{Key Words}

Thrombosis; Heart Valve Prosthesis; Blood Coagulation.

Mailing Address: Márcio Silva Miguel Lima •

Av. Dr. Enéas de Carvalho Aguiar, 44 - 05403-900 - São Paulo, SP, Brasil

E-mail: marcio.lima@incor.usp.br

Manuscript received October 07, 2008; revised manuscript received February 06, 2009; accepted May 15, 2009 